\title{
BAROREFLEX ACTIVATION THERAPY (BAT) EFFECTIVENESS AMONG HEART FAILURE PATIENTS: A SYSTEMATIC REVIEW AND META-ANALYSIS
}

\section{Farahdina Farahdina, Muhammad Ilham Hernawan, Wiryantari Akhdani Pratiwi, Hapsary Puteri Widodo, Vatine Adila}

Brawijaya University, Airlangga University

E-mail: farahdina95@gmail.com,muhammadilhamhernawan@gmail.com, wiryantari20@gmail.com, emailhapsary@gmail.com, vatineadila@gmail.com

\begin{tabular}{|c|c|}
\hline ARTICLE INFO & ABSTRACT \\
\hline $\begin{array}{l}\text { Received: } \\
\text { July, 24th } 2021 \\
\text { Revised: } \\
\text { August, } 14^{\text {th }} 2021 \\
\text { Approved: } \\
\text { August, } 16^{\text {th }} 2021\end{array}$ & $\begin{array}{l}\text { Heart failure is promoted by the imbalance of } \\
\text { sympathovagal, which increased sympathetic and decreased } \\
\text { parasympathetic activity. BAT, an electrical stimulation } \\
\text { technology, cause the baroreflex to be activated and balances } \\
\text { the sympathovagal. Systematic review and meta-analysis } \\
\text { were conducted, including published reports about the } \\
\text { effectiveness of BAT in heart failure patients from PubMed, } \\
\text { Embase, Cochrane, and Google Scholar to calculate the } \\
\text { pooled standard mean difference and 95\% confidence interval } \\
\text { (95\% CI) using either random or fixed effect model. Our } \\
\text { search strategy identified } 161 \text { possible studies. Thirteen } \\
\text { studies have been included as a full-text review. We excluded } \\
\text { seven of these papers due to review, and our analysis has } \\
\text { included six papers. Our combined analysis has shown that } \\
\text { BAT is associated with an improvement in NYHA class } \\
\text { compared to control (0.19[95\%Cl: 0.11-0.31], p=0.000). Our } \\
\text { pooled analysis also found that BAT, compared to control, } \\
\text { was associated with 6-MHWD improvement, (-136.25[95\%Cl: } \\
\text {-181.34--91.17], p } 0.000 \text { ). Our pooled analysis also found } \\
\text { that BAT, compared to control, was associated with HF } \\
\text { hospitalization (-6.38[95\%Cl: -8.46--4.30], p = 0.000). BAT } \\
\text { has a significant effect on improving NYHA Class, 6-minute } \\
\text { hall walk distance, and decreasing HF patient's }\end{array}$ \\
\hline
\end{tabular}

Farahdina Farahdina, Muhammad Ilham Hernawan, Wiryantari Akhdani Pratiwi, Hapsary Puteri Widodo, Vatine Adila. (2021). Baroreflex Activation Therapy (BAT) Effectiveness among Heart Failure Patients: A Systematic

How to cite:

E-ISSN: Review and Meta-Analysis. Journal Eduvest. 1(8): 717-727

Published by: 


\section{Farahdina Farahdina, Muhammad Ilham Hernawan, Wiryantari Akhdani Pratiwi, Hapsary Puteri Widodo, Vatine Adila}

\begin{tabular}{ll}
\hline & $\begin{array}{l}\text { hospitalization days. Meanwhile, there is an insignificancy on } \\
\text { LVEF and QoL improvement in HF patients. Future studies are } \\
\text { still needed. }\end{array}$ \\
\hline KEYWORDS & BAT, baroreflex, HF, NYHA, LVEF \\
\hline C) (i) (-) & $\begin{array}{l}\text { This work is licensed under a Creative Commons } \\
\text { Attribution-ShareAlike 4.0 International License }\end{array}$ \\
\hline
\end{tabular}

\section{INTRODUCTION}

Heart failure (HF) is a complex clinical syndrome, with the character of the heart's reduced ability to pump and/or fill with blood. Physiologically, heart failure can be defined as an inadequate cardiac output to meet metabolic demands or adequate cardiac output secondary to compensatory neurohormonal activation (Savarese \& Lund, 2017). HF affect 26 million people worldwide. In 2012, HF was responsible for an estimated health expenditure of around $\$ 31$ billion, or more than $10 \%$ of the total health expenditure for cardiovascular diseases in the United States (Mozaffarian et al., 2016). It is estimated that the total cost expected to increase by $127 \%$ between 2012 and 2030. In Indonesia, heart failure had become the most leading cause for hospitalization beside acute coronary syndrome (ACS) with high mortality and readmission rate (Siswanto, 2013).

One of the therapies that has shown in the preliminary study of heart failure is Baroreceptor Activation Therapy (BAT). BAT is an electrical stimulation technology that causes the baroreflex to be activated, decreases the activity of the sympathetic nerves, and increased the parasympathetic activity by stimulating the carotid sinus using an implanted device resembling a cardiac pacemaker. This stimulation results in increased arterial and venous compliance and reduced peripheral resistance. By doing so, BAT can improve the clinical status of a patient with HF (Abraham et al., 2015; Gronda et al., 2014; Zile, Abraham, Weaver, Butter, Ducharme, Halbach, Klug, Lovett, Müller-Ehmsen, et al., 2015).

Our present study aimed to perform a meta-analysis regarding the baroreceptor activation therapy in heart failure with reduced ejection fraction and the outcome to assess the baroreceptor activation therapy's efficacy. Based on the evidence-based, we hypothesized that Baroreceptor Activation Therapy (BAT) associated with improvement of Quality of Life (QoL) score, NYHA Class, LVEF, 6-Minute Hall Walk Distance (6MHWD), and decreased the hospitalization rate and the average number of days hospitalization.

\section{RESEARCH METHODS}

This systematic review and meta-analysis were conducted from August to September 2020 to determine the effectiveness of Baroreflex Activation Therapy (BAT) in heart failure. Published reported from PubMed, Embase, Cochrane, and Google Scholar were conducted to calculate the pooled standard mean difference and $95 \%$ confidence interval $(95 \% \mathrm{CI})$ using either random or fixed effect model. The current study has applied to ensure that our procedures, including record collection, extraction of data, quality evaluation, and statistical analysis, adhere to the PRISMA guideline from Preferred Reporting Items for Systematic Examination and Meta-Analysis (PRISMA).

Several scientific references (PubMed, Embase, Cochrane, and Google Scholar) were searched for studies assessing Baroreflex Activation Therapy (BAT)'s efficacy in heart failure patients until September 15, 2020. We restricted the publishing language. 
We did not include these characteristics in our study if published papers were not found in both English and Indonesia. In addition, the following keywords were used to perform a systemic search: ["Heart Failure" or "CHF" or "Congestive Heart Failure"] and ["Baroreflex Activation Therapy" or "BAT"] and ["Efficacy"]. If we found documents with the same study details, we included only documents with larger samples in our search strategy. Additionally, the following information of interest was extracted from each paper: (1) first author name, (2) year of publication, (3) sample size of case and control, (4) age of participants, (5) ethnicity, (6) main findings, (7) Quality of Life score of case and control, (8) NYHA class of case and control, (9) 6-Minute Hall Walk Distance (6MHWD) of case and control, (10) Left Ventricular Ejection Fraction (LVEF), and (10) the hospitalization of heart failure patients of case and control. To provide highvalidity data, two independent authors performed data extraction to avoid human error (FF, WAP). If a discrepancy was found, we performed a discussion with other authors (MIH, HPW).

The articles in our analysis were based on the following criteria: (1) assessing the effectiveness of Baroreflex Activation Therapy (BAT) in treating heart failure patients; and (2) having required data for calculation of standard mean difference and $95 \% \mathrm{CI}$. Furthermore, the criteria of exclusion were as follows: (1) unrelated titles and abstracts, (2) reviews, (3) incomplete and or ungeneralized data, and (4) have a deviation from Hardy-Weinberg equilibrium (X2 > 3.84 was defined as deviation from Hardy-Weinberg equilibrium).

Our present study's predictor covariate was Baroreflex Activation Therapy (BAT) effectiveness in treating heart failure patients. The outcome parameters were the QoL score, NYHA class, 6-Minute Hall Walk Distance (6-MHWD), Left Ventricular Ejection Fraction (LVEF), and heart failure hospitalization. They were determined after we performed initial searching for covariates screening to include in our meta-analysis calculation.

Prior to the meta-analysis, the quality measured every paper using the scale of New Castle-Ottawa (NOS) (Bae, 2016). The NOS score ranged from 0 to 9 and had three points: patient selection (4 points), group comparability (2 points), and exposure measurement ( 3 points). The paper was interpreted to be of low quality (for scores 4 ), of moderate rate (for scores 5-6), and of high quality (for scores 7). Low-quality papers have not been included in our study. Two independent investigators (FF and $\mathrm{MIH}$ ) carried out the NOS assessment, who discussed with the others (HPW, WAP) where there was a discrepancy.

The correlation and effect estimates of Baroreflex Activation Therapy (BAT) on heart failure patients with the QoL score, NYHA class, 6-Minute Hall Walk Distance (6MHWD), Left Ventricular Ejection Fraction (LVEF), and heart failure hospitalization were assessed using a $\mathrm{Z}$ test. Data for heterogeneity and potential publication bias were assessed before the significant factors were identified. The heterogeneity was evaluated with the Q test. In the case of heterogeneity $(p<0,10)$, a random effect model has been adopted, or a fixed effect model has been applied. To determine reporting and publishing errors, the Egger and funnel plot test $(\mathrm{p}<0.05$ was considered publication bias). The correlation and impact assessments were then presented using the forest plot. Review Manager 5.4 (Revman Cochrane, London, UK) and Comprehensive Meta-Analysis software (version 3.3.070, Biostat Inc., Englewood, NJ, USA) were used to analyze the data. Two independent authors (FF and $\mathrm{MIH}$ ) performed statistical analyses in order to avoid methodological errors. 


\section{Farahdina Farahdina, Muhammad Ilham Hernawan, Wiryantari Akhdani \\ Pratiwi, Hapsary Puteri Widodo, Vatine Adila}

\section{RESULTS AND DISCUSSION}

\section{A. Eligible studies}

Our search strategy identified 161 possible studies. One hundred forty-eight of them were excluded on the basis of titles and abstracts, which did not concern them. A total of 13 studies have been included as a full-text review. We excluded seven of these papers due to review $(\mathrm{n}=3)$, incomplete $(\mathrm{n}=2)$ and poor quality $(\mathrm{n}=2)$ data. Finally, our analysis has included six papers. The paper selection route in our study is summarized in Figure 1, and the baseline characteristics of the papers included in our meta-analysis are described in Table 1.

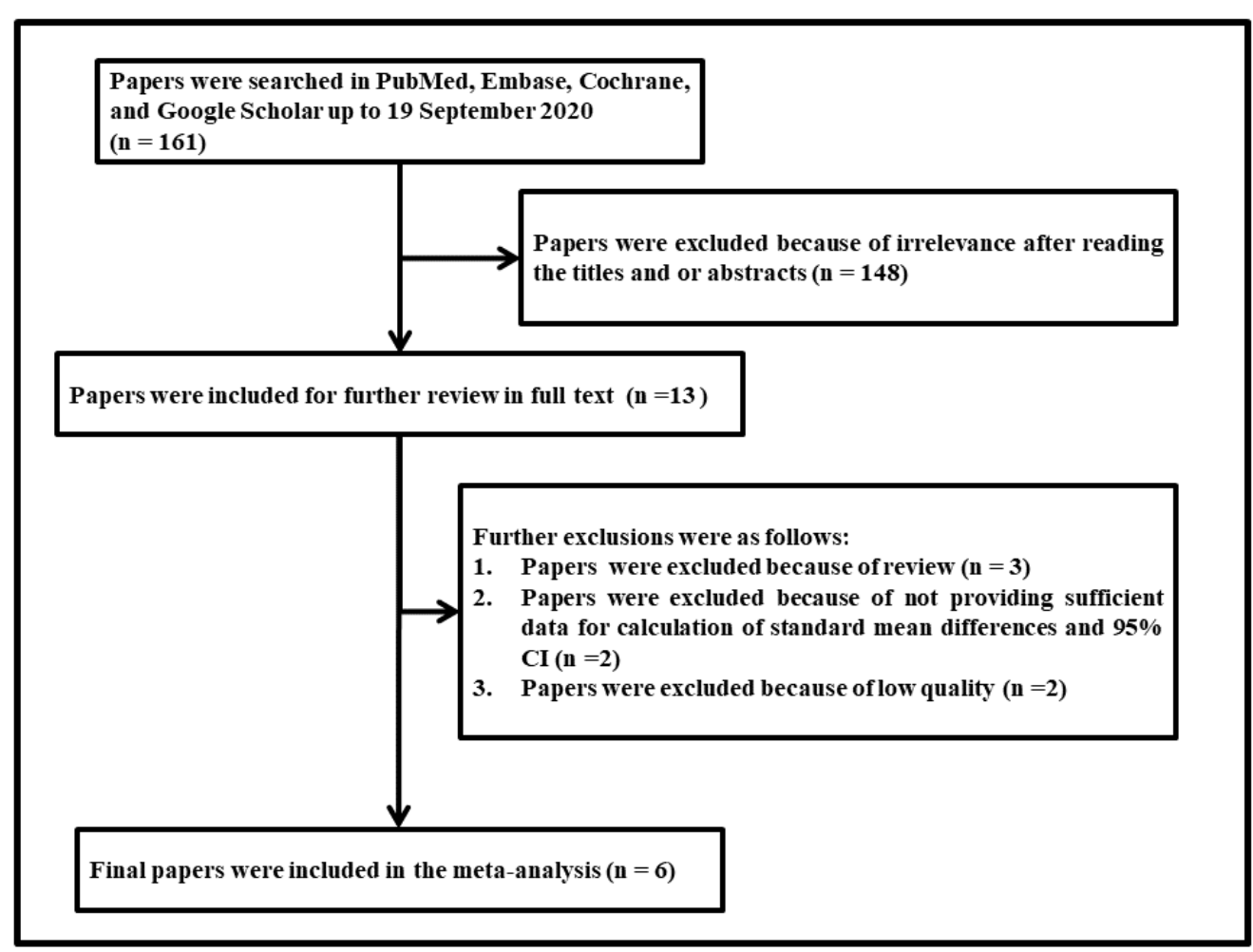

Figure 1. A flowchart of study selection in our study

Table 1. Baseline characteristics of articles included in our study

\begin{tabular}{|c|c|c|c|c|c|c|c|}
\hline \multirow{2}{*}{$\begin{array}{l}\text { Author } \\
\& \text { year }\end{array}$} & \multicolumn{2}{|c|}{ Sample size } & \multirow{2}{*}{$\begin{array}{l}\text { Case } \\
\text { setting }\end{array}$} & \multirow{2}{*}{$\begin{array}{l}\text { Age } \\
\text { (years) }\end{array}$} & \multirow[t]{2}{*}{ Ethnicity } & \multirow[t]{2}{*}{ NOS } & \multirow[t]{2}{*}{ Main findings } \\
\hline & $\mathrm{CON}$ & BAT & & & & & \\
\hline $\begin{array}{l}\text { Abraham } \\
\text { et al., } \\
2015\end{array}$ & 54 & 64 & $\begin{array}{l}\text { HF } \\
\text { NYHA } \\
\text { class III }\end{array}$ & $65 \pm 12$ & Caucasian & 7 & $\begin{array}{l}\text { BAT is tolerable } \\
\text { and improves } \\
\text { functional status, } \\
\text { quality of life, and } \\
\text { hospitalizations in } \\
\text { HF NYHA class III } \\
\text { patients (Abraham } \\
\text { et al., 2015). }\end{array}$ \\
\hline $\begin{array}{l}\text { Dell-oro } \\
\text { et al., } \\
2017\end{array}$ & 17 & 7 & $\begin{array}{l}\mathrm{HF} \\
\text { NYHA } \\
\text { class III }\end{array}$ & $67 \pm 3$ & Caucasian & 7 & $\begin{array}{l}\text { This study provides } \\
\text { evidence that BAT } \\
\text { in heart failure with }\end{array}$ \\
\hline
\end{tabular}




\begin{tabular}{|c|c|c|c|c|c|c|c|}
\hline & & & & & & & $\begin{array}{l}\text { reduced ejection } \\
\text { fraction allows not } \\
\text { only to improve } \\
\text { hemodynamic and } \\
\text { clinical profile but } \\
\text { also to allow an } \\
\text { almost complete } \\
\text { restoration of the } \\
\text { sympathetic neural } \\
\text { function's } \\
\text { physiological levels } \\
\text { (Dell'Oro et al., } \\
\text { 2017). }\end{array}$ \\
\hline $\begin{array}{l}\text { Gronda } \\
\text { et al., } \\
2014\end{array}$ & 11 & 11 & $\begin{array}{l}\text { HF } \\
\text { NYHA } \\
\text { class III }\end{array}$ & $67 \pm 9$ & Caucasian & 7 & $\begin{array}{l}\text { BAT was safe and } \\
\text { provided a long } \\
\text { term improvement } \\
\text { in MSNA and } \\
\text { clinical variables. } \\
\text { Based on the } \\
\text { present } \\
\text { understanding of } \\
\text { HF } \\
\text { pathophysiology, } \\
\text { these results } \\
\text { suggest that BAT } \\
\text { may improve } \\
\text { outcomes in HF by } \\
\text { modulating } \\
\text { autonomic } \\
\text { balance.(Gronda et } \\
\text { al., 2014) }\end{array}$ \\
\hline $\begin{array}{l}\text { Gronda } \\
\text { et al., } \\
2016\end{array}$ & 9 & 9 & $\begin{array}{l}\text { HF } \\
\text { NYHA } \\
\text { class III }\end{array}$ & $67 \pm 10$ & Caucasian & 7 & $\begin{array}{l}\text { This study showed } \\
\text { that BAT } \\
\text { significantly } \\
\text { reduced MSNA and } \\
\text { has clinical } \\
\text { improvement, but } \\
\text { does not appear to } \\
\text { modify arterial } \\
\text { stiffness within this } \\
\text { HFrEF cohort } \\
\text { chronically (Gronda } \\
\text { et al., 2016). }\end{array}$ \\
\hline $\begin{array}{l}\text { Halbach } \\
\text { et al., } \\
2018\end{array}$ & 36 & 47 & $\begin{array}{l}\text { HF } \\
\text { NYHA } \\
\text { class III }\end{array}$ & - & Caucasian & 6 & $\begin{array}{l}\text { No significant } \\
\text { differences were } \\
\text { found in BAT } \\
\text { efficacy or safety } \\
\text { between patients } \\
\text { with and without } \\
\text { CAD, indicating } \\
\text { that BAT improves } \\
\text { exercise capacity, } \\
\text { quality of life, and } \\
\text { NTproBNP in } \\
\text { patients with }\end{array}$ \\
\hline
\end{tabular}




\section{Farahdina Farahdina, Muhammad Ilham Hernawan, Wiryantari Akhdani Pratiwi, Hapsary Puteri Widodo, Vatine Adila}

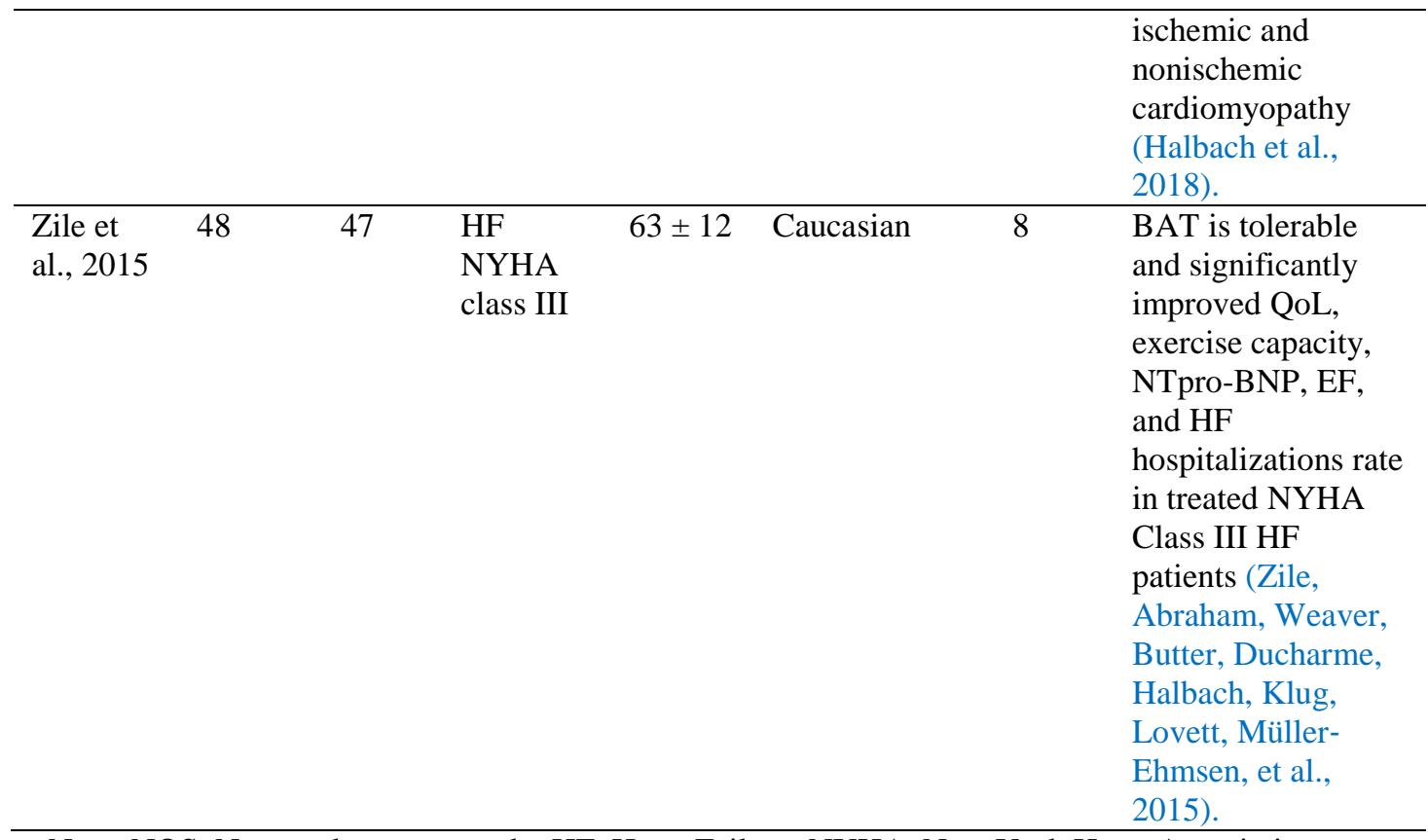

Note, NOS, Newcastle-ottawa scale; HF, Heart Failure; NYHA, New York Heart Association;

CON, Control; BAT, Baroreflex Activation Therapy

\section{B. Data synthesis}

We included six papers evaluating the association between Baroreflex Activation Therapy (BAT) and QoL score, five papers evaluating the correlation between Baroreflex Activation Therapy (BAT) and NYHA class improvement, six papers evaluating the association of Baroreflex Activation Therapy (BAT) and 6-MHWD, six papers evaluating the relationship between Baroreflex Activation Therapy (BAT) and LVEF, and four papers evaluating the relationship between Baroreflex Activation Therapy (BAT) and HF hospitalization. Our combined analysis has shown that Baroreflex Activation Therapy (BAT) is associated with an improvement in NYHA class compared to control (OR: 0.19 [95\% CI: 0.11-0.31], $\mathrm{p}=0.000$ ). Our pooled analysis also found that Baroreflex Activation Therapy (BAT), compared to control, was associated with 6-MHWD improvement, (mean diff: -136.25 [95\%CI: -181.34 - -91.17], $\mathrm{p}=0.000$ ). Our pooled analysis also found that Baroreflex Activation Therapy (BAT), compared to control, was associated with HF hospitalization, (mean diff: -6.38 [95\%CI: $-8.46--4.30$ ], $\mathrm{p}=0.000$ ). However, QoL score (mean diff: -16.46 [95\%CI: -40.30 - 7.38], $\mathrm{p}=0.18$ ) and LVEF (mean diff: -7.49 [95\%CI: $-12.59-2.39$ ], $\mathrm{p}=0.004$ ) were not affected significantly between Baroreflex Activation Therapy (BAT), and control group. The summary of the correlation and effect estimates between Baroreflex Activation Therapy (BAT) and outcome measures in our present study is outlined in Table 2 and Figure 2. 
Table 2. Summary of the association between Baroreflex Activation Therapy and Outcome Parameters among Heart Failure Patients in our study

\begin{tabular}{|c|c|c|c|c|c|c|c|c|c|}
\hline \multirow{2}{*}{$\begin{array}{l}\text { Outcome } \\
\text { parameters }\end{array}$} & \multirow{2}{*}{\multicolumn{2}{|c|}{ NS }} & \multirow[t]{2}{*}{ Model } & Outcome measure & \multirow{2}{*}{$\begin{array}{c}\text { Mean } \\
\text { difference / } \\
\text { OR }\end{array}$} & \multirow[t]{2}{*}{$95 \% \mathrm{CI}$} & \multirow{2}{*}{\multicolumn{2}{|c|}{$\mathrm{pE}$}} & \multirow[t]{2}{*}{$\mathrm{p}$} \\
\hline & & & & Control BAT & & & & & \\
\hline
\end{tabular}

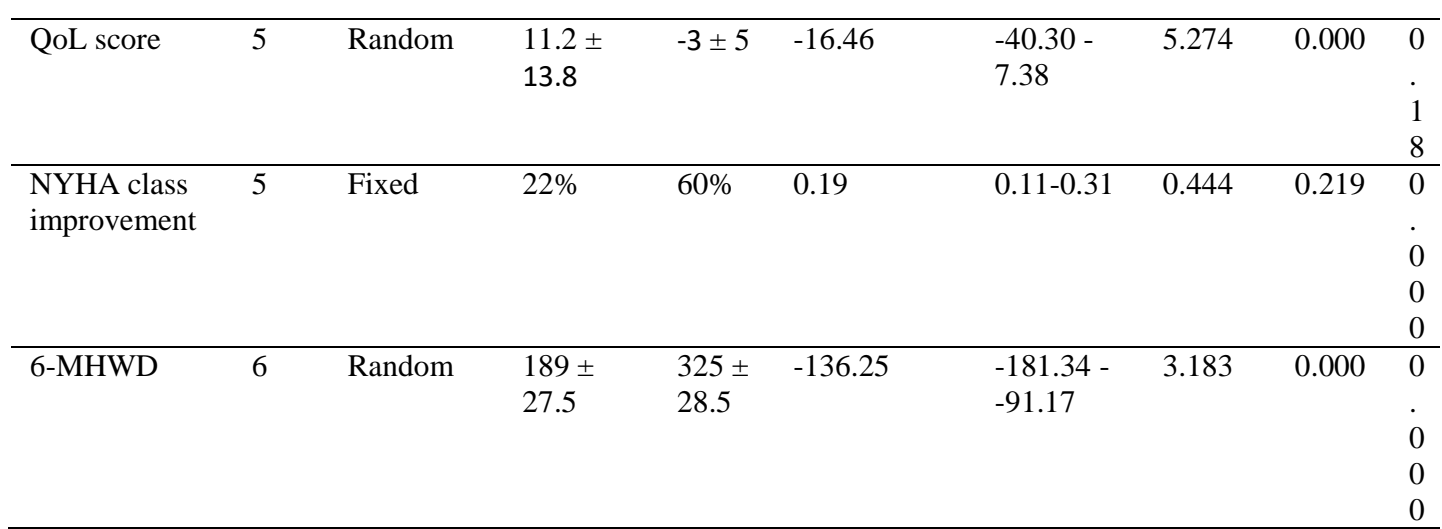

Note, data were presented in mean \pm SD; NS, number of study; QoL, quality of life; NYHA, New York Heart Association; MHWD, minute hall walk distance; LVEF, left ventricular ejection fraction; CI, confidence interval; $\mathrm{pE}$, p Egger; pHet, p Heterogeneity.

A).

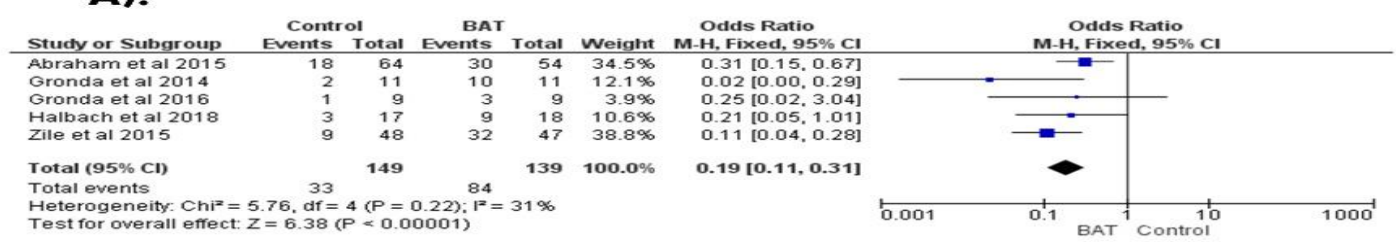

B).

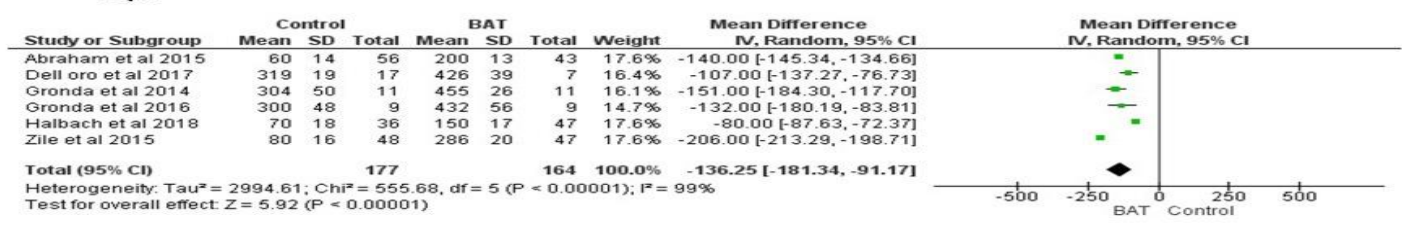

C).

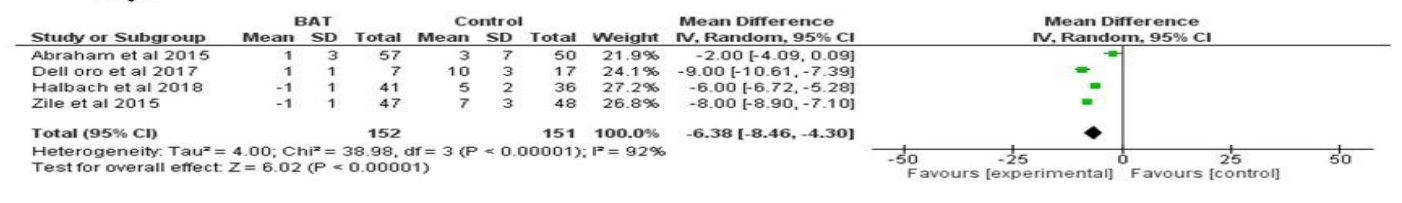

Figure 2. Forest plot of the association between Baroreflex Activation Therapr (BAT) and outcome parameters among heart failure patients. A). NYHA Class. B). SMHWD. C). HF HOSpitalization 


\section{Farahdina Farahdina, Muhammad Ilham Hernawan, Wiryantari Akhdani \\ Pratiwi, Hapsary Puteri Widodo, Vatine Adila}

\section{Source of heterogeneity \\ Heterogeneity among studies}

The evidence for heterogeneity in the following covariates has been identified in our study: QoL score, 6-Minute Hall Walk Distance (6MHWD), Left Ventricular Ejection Fraction (LVEF), and heart failure hospitalization. Therefore, random effect model was used to assess the association between Baroreflex Activation Therapy (BAT) and the QoL score, 6-Minute Hall Walk Distance (6MHWD), Left Ventricular Ejection Fraction (LVEF), and heart failure hospitalization. In comparison, NYHA class covariate, we find no heterogeneity. Therefore, the associations between Baroreflex Activation Therapy (BAT) and NYHA class were tested using a fixed-effect model. Table 2 explains the proof of heterogeneity between studies in our present meta-analysis.

\section{Potential publication bias}

We used the Egger test to assess the possible differences between studies. Overall, our studies did not contain any publication bias. Table 2 explains the description of the discrimination to publications.

\section{Discussion}

Overall studies showed significant effects of Baroreflex Activation Therapy (BAT) in improvement of NYHA Class and 6-minute hall walk distance (6-MHWD) and decreased hospitalization days for Heart Failure patients. But there is insignificancy of Baroreceptor Activation Therapy efficacy towards LVEF and QoL improvement. Five of six studies showed that Baroreflex Activation Therapy (BAT) effectively improves NYHA class among heart failure patients. On the other hand, another study could not validate their efficacy in improving the NYHA class among HF patients. Moreover, six studies showed that Baroreflex Activation Therapy (BAT) effectively improves 6MHWD among HF patients. Our pooled analysis revealed that the improvement of NYHA class and 6-MHWD were observed in patients given Baroreflex Activation Therapy (BAT) compared to heart failure patients without Baroreflex Activation Therapy (BAT). This study has never been reported before, but only one systematic review reported it. Our findings were consistent with the previous review. They also found that Baroreflex Activation Therapy (BAT) effectively improve NYHA class and 6-MHWD among heart failure patients (Schmidt, Rodrigues, Schmidt, \& Irigoyen, 2020). Furthermore, in other settings, a meta-analysis was performed to identified the correlation of Baroreflex Activation Therapy (BAT) and reduced of blood pressure. Yet they revealed that Baroreflex Activation Therapy (BAT) effectively reduced blood pressure in chronic heart failure patients (Wallbach et al., 2016). This study makes us think that Baroreflex Activation Therapy (BAT) may also be effective for heart failure patients in other factors. However, theoretically, decreased baroreceptor sensitivity and increased arterial stiffness are associated with increased sympathetic nerves that may increase peripheral vascular resistance, which can decrease ejection fraction and therefore decrease exercise capacity. Thus, baroreceptor activation therapy may reduce this sympathetic activation, coupled with an increase in parasympathetic activity (Abraham et al., 2015). This explanation might be underlying factors that Baroreflex Activation Therapy (BAT) improves HF patients' functional status as assessed by NYHA Class improvement and 6-MHWD.

Besides NYHA class and 6-MHWD related to BAT revealed to have significant effects among HF patients, HF hospitalization also had significant improvement on BAT patients. Four of the six studies were analyzed and showed that Baroreflex Activation 
Therapy (BAT) significantly improved hospitalizations among heart failure patients. This result is consistent with the previous review. They revealed that BAT lower hospitalization rates and the number of days hospitalization after treatment (Schmidt et al., 2020). In other meta-analysis settings, there was no explanation about the hospitalization effect after BAT because they just explain its impact on reduced blood pressure among chronic heart failure patients (Wallbach et al., 2016). However, theoretically, increased sympathetic activity and decreased parasympathetic activity occur as compensatory mechanisms in heart failure. But in a long time, it can worsen heart failure. Baroreflex activation therapy (BAT) produces centrally mediated sympathetic outflow and increases parasympathetic activity. So, heart failure progression may be reduced and reduced the HF hospitalization rate and the average number of days hospitalization. The decrease of muscle sympathetic nerve activity (MSNA) directly measured in the peroneal nerve via the microneurographic technique was correlated to the reduction of HF hospitalization rate, which also improved clinical status (Gronda et al., 2014). This explanation might be underlying factors that Baroreflex Activation Therapy (BAT) reduced HF hospitalization rate and the average number of days hospitalization.

A total of two parameters were insignificant in our analysis. That two were the QoL score and LVEF reduction. BAT's pathophysiology in failed to improve LVEF is still unclear, may be due to the contribution of decreased sympathetic nerve activity associated with BAT, which also reduces the contractility of the heart muscle and makes the ejection fraction still consist the same and not significantly improve (Abraham et al., 2015). The QoL score may have many contributing factors, such as the limitation of sample study size, cofounding factors, comorbid diseases, lifestyle, gender, and medication adherence that interfered with the patient's QoL score.

\section{E. Clinical Implication}

Despite the fact that we provided the evidence of BAT efficacy as a treatment for HF patients in the term of NYHA class, 6-MHWD, and rate and an average number of hospitalization, however, we believed that there is a possibility that BAT can improve LVEF and QoL, but, because our data have limitation sample population, the further studies with a higher population may be required. The use of BAT in addition to GDMT can be considered because it has better results than GDMT alone.

\section{CONCLUSION}

Our study reveals that Baroreflex Activation Therapy (BAT) has a significant effect on improving NYHA Class, 6-minute hall walk distance and decreasing hospitalization days for HF patients. On the other side, there is an insignificancy effect on LVEF and QoL improvement in HF patients. Our study is the first review with metaanalysis to conclude BAT's efficacy in treating HF patients. Whether in the bigger sample size and heterogeneity across the included literature, BAT correlates with LVEF, and QoL improvement remains to be clarified by future studies.

\section{REFERENCES}

Abraham, William T., Zile, Michael R., Weaver, Fred A., Butter, Christian, Ducharme, Anique, Halbach, Marcel, Klug, Didier, Lovett, Eric G., Müller-Ehmsen, Jochen, \& Schafer, Jill E. (2015). Baroreflex activation therapy for the treatment of heart failure with a reduced ejection fraction. JACC: Heart Failure, 3(6), 487-496.

Bae, Jong Myon. (2016). A suggestion for quality assessment in systematic reviews of 


\section{Farahdina Farahdina, Muhammad Ilham Hernawan, Wiryantari Akhdani Pratiwi, Hapsary Puteri Widodo, Vatine Adila}

observational studies in nutritional epidemiology. Epidemiology and Health, 38.

Dell'Oro, Raffaella, Gronda, Edoardo, Seravalle, Gino, Costantino, Giuseppe, Alberti, Luca, Baronio, Barbara, Staine, Tiziana, Vanoli, Emilio, Mancia, Giuseppe, \& Grassi, Guido. (2017). Restoration of normal sympathetic neural function in heart failure following baroreflex activation therapy: final 43-month study report. Journal of Hypertension, 35(12), 2532.

Gronda, Edoardo, Brambilla, GianMaria, Seravalle, Gino, Maloberti, Alessandro, Cairo, Matteo, Costantino, Giuseppe, Lovett, Eric, Vanoli, Emilio, Mancia, Giuseppe, \& Grassi, Guido. (2016). Effects of chronic carotid baroreceptor activation on arterial stiffness in severe heart failure. Clinical Research in Cardiology, 105(10), 838-846.

Gronda, Edoardo, Seravalle, Gino, Brambilla, Gianmaria, Costantino, Giuseppe, Casini, Andrea, Alsheraei, Ali, Lovett, Eric G., Mancia, Giuseppe, \& Grassi, Guido. (2014). Chronic baroreflex activation effects on sympathetic nerve traffic, baroreflex function, and cardiac haemodynamics in heart failure: a proof-of-concept study. European Journal of Heart Failure, 16(9), 977-983.

Halbach, Marcel, Abraham, William T., Butter, Christian, Ducharme, Anique, Klug, Didier, Little, William C., Reuter, Hannes, Schafer, Jill E., Senni, Michele, \& Swarup, Vijay. (2018). Baroreflex activation therapy for the treatment of heart failure with reduced ejection fraction in patients with and without coronary artery disease. International Journal of Cardiology, 266, 187-192.

Mozaffarian, Dariush, Benjamin, Emelia J., Go, Alan S., Arnett, Donna K., Blaha, Michael J., Cushman, Mary, Das, Sandeep R., Ferranti, Sarah De, Després, Jean Pierre, Fullerton, Heather J., Howard, Virginia J., Huffman, Mark D., Isasi, Carmen R., Jiménez, Monik C., Judd, Suzanne E., Kissela, Brett M., Lichtman, Judith H., Lisabeth, Lynda D., Liu, Simin, MacKey, Rachel H., Magid, David J., McGuire, Darren K., Mohler, Emile R., Moy, Claudia S., Muntner, Paul, Mussolino, Michael E., Nasir, Khurram, Neumar, Robert W., Nichol, Graham, Palaniappan, Latha, Pandey, Dilip K., Reeves, Mathew J., Rodriguez, Carlos J., Rosamond, Wayne, Sorlie, Paul D., Stein, Joel, Towfighi, Amytis, Turan, Tanya N., Virani, Salim S., Woo, Daniel, Yeh, Robert W., \& Turner, Melanie B. (2016). Heart disease and stroke statistics-2016 update a report from the American Heart Association. In Circulation (Vol. 133). https://doi.org/10.1161/CIR.0000000000000350

Savarese, Gianluigi, \& Lund, Lars H. (2017). Global public health burden of heart failure. Cardiac Failure Review, 3(1), 7.

Schmidt, Rodrigo, Rodrigues, Clarissa Garcia, Schmidt, Kelen Heinrich, \& Irigoyen, Maria Claudia Costa. (2020). Safety and efficacy of baroreflex activation therapy for heart failure with reduced ejection fraction: a rapid systematic review. ESC Heart Failure, 7(1), 3-14.

Siswanto, Bambang Budi. (2013). Heart Failure in Indonesia. Journal of Cardiac Failure, 19(10), S108. https://doi.org/10.1016/j.cardfail.2013.08.027

Wallbach, Manuel, Halbach, Marcel, Reuter, Hannes, Passauer, Jens, Lüders, Stephan, Böhning, Enrico, Zenker, Dieter, Müller, Gerhard A., Wachter, Rolf, \& Koziolek, Michael J. (2016). Baroreflex activation therapy in patients with prior renal denervation. Journal of Hypertension, 34(8), 1630-1638.

Zile, Michael R., Abraham, William T., Weaver, Fred A., Butter, Christian, Ducharme, Anique, Halbach, Marcel, Klug, Didier, Lovett, Eric G., Müller-Ehmsen, Jochen, Schafer, Jill E., Senni, Michele, Swarup, Vijay, Wachter, Rolf, \& Little, William C. (2015). Baroreflex activation therapy for the treatment of heart failure with a reduced ejection fraction: Safety and efficacy in patients with and without cardiac 
resynchronization therapy. European Journal of Heart Failure, 17(10), 1066-1074. https://doi.org/10.1002/ejhf.299

Zile, Michael R., Abraham, William T., Weaver, Fred A., Butter, Christian, Ducharme, Anique, Halbach, Marcel, Klug, Didier, Lovett, Eric G., Müller-Ehmsen, Jochen, \& Schafer, Jill E. (2015). Baroreflex activation therapy for the treatment of heart failure with a reduced ejection fraction: safety and efficacy in patients with and without cardiac resynchronization therapy. European Journal of Heart Failure, 17(10), 1066-1074. 